\title{
Mesothelioma with non-pleural malignancy: a red herring or just an uncommon pairing?
}

\author{
Andrew J Drain, Kourosh Saeb-Parsy, Amit K Shah, D Rassl and \\ Andrew J Ritchie*
}

Address: Papworth Hospital, Papworth Everard, Cambridge CB3 8RE, UK

Email: Andrew J Drain - andrewdrain@doctors.org.uk; Kourosh Saeb-Parsy - kourosh_saeb_parsy@yahoo.co.uk; Amit K Shah - as329@hotmail.com; D Rassl - d.rassl@papworth.nhs.uk; Andrew J Ritchie* - Andrew.Ritchie@papworth.nhs.uk

* Corresponding author

Published: 0 I November 2006

Journal of Cardiothoracic Surgery 2006, 1:39 doi:10.1 186/1749-8090-1-39
Received: 26 June 2006

Accepted: 0I November 2006

This article is available from: http://www.cardiothoracicsurgery.org/content/I/I/39

(C) 2006 Drain et al; licensee BioMed Central Ltd.

This is an Open Access article distributed under the terms of the Creative Commons Attribution License (http://creativecommons.org/licenses/by/2.0), which permits unrestricted use, distribution, and reproduction in any medium, provided the original work is properly cited.

\begin{abstract}
Malignant pleural mesothelioma (MPM) is a highly aggressive cancer of the pleura with a wellestablished male predominance and causative link with asbestos exposure. We report four cases of female patients with MPM referred for palliation of symptoms thought to be due to previous non-pleural malignancy.

With emerging novel treatments for MPM, this article discusses four unusual cases of MPM occurring in the setting of other malignancy, highlights the importance of considering a primary diagnosis of MPM even in patients with other malignancy, and reinforces the benefits of videoassisted surgical biopsy which allows simultaneous diagnosis and treatment.
\end{abstract}

\section{Case reports}

Four female patients were referred to our institution for definitive treatment of pleural effusion (and one for persistent pneumothorax). All had undergone CT imaging and pleural fluid examination. In all cases the fluid was diagnostic for malignancy but not for MPM. Assuming the pleural effusions to be metastatic from their previous malignancy, they were referred for surgical palliative management.

The first case was a 59-year-old woman with a history of right-sided adenocarcinoma of the breast for which she underwent mastectomy. After presenting 10 years later with a right-sided pleural effusion and chest wall nodules, she received anastrazole (aromatase inhibitor) and six cycles of docetaxel (taxane) resulting in complete remission of the chest wall disease. The right-sided pleural effusion persisted despite five separate episodes of drainage and so she underwent right-sided video-assisted thoracoscopic surgical (VATS) cytoreductive pleurectomy. The tumour was histologically confirmed to be MPM of the epithelioid type (see Figure 1 and 2). A previous history of asbestos exposure was not confirmed.

The second case involved a 78-year-old woman with a history of right-sided adenocarcinoma of the breast treated with mastectomy and post-operative radiotherapy. She presented 38 years later with a persistent right-sided pleural effusion. Cytological examination of the pleural aspirate showed adenocarcinoma cells consistent with primary breast origin. She was referred for VATS cytoreductive pleurectomy and at operation was found to have infiltration of the pleura with tumour, histologically confirmed to be MPM of the epithelioid type. A previous history of asbestos exposure was not confirmed. 


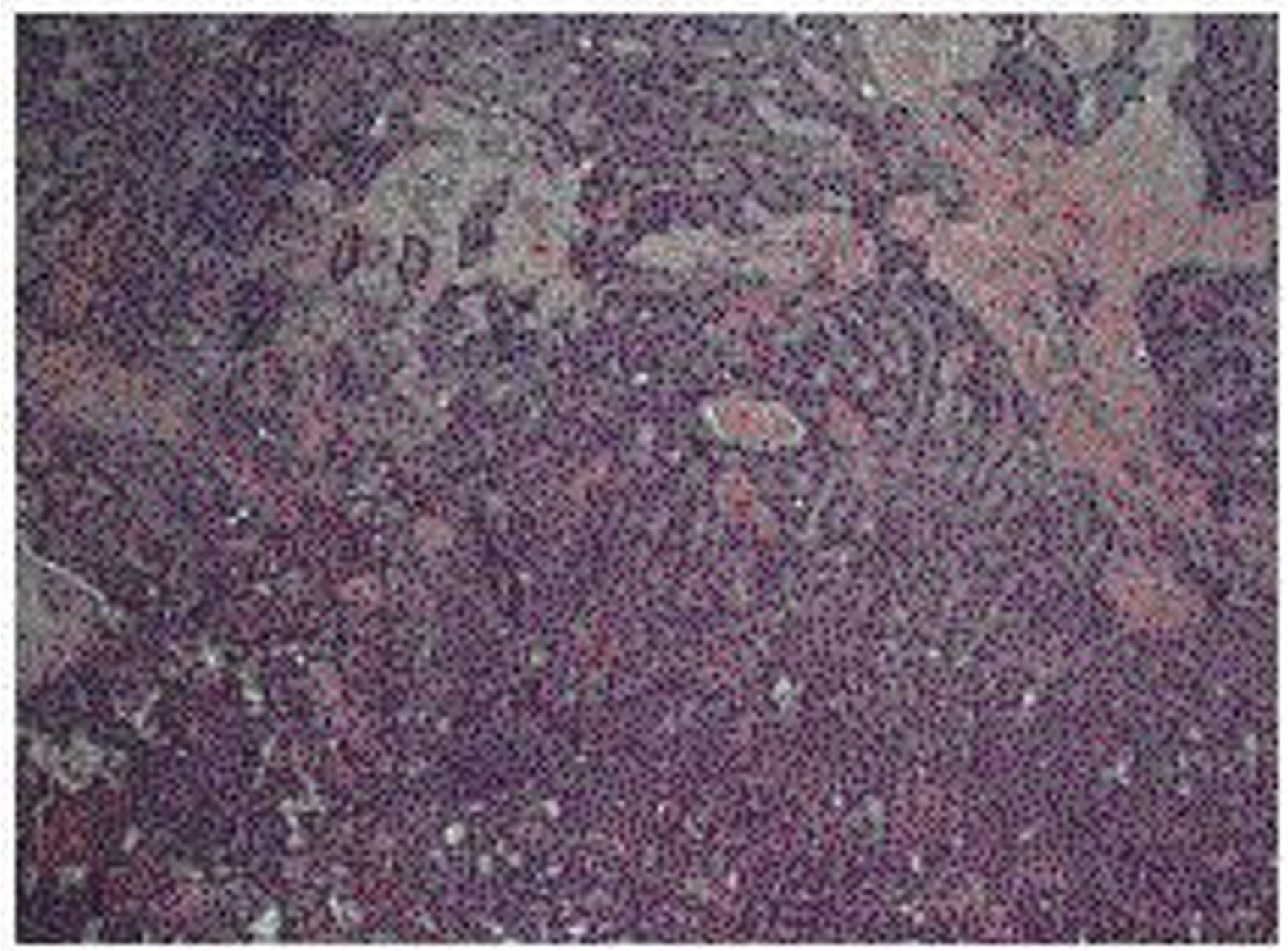

Figure I

Histology demonstrating epithelioid mesothelioma $\left\{\begin{array}{ll}x & 100\}\end{array}\right.$.

The third case was a 74-year-old woman with a history of endometrial carcinoma for which she underwent a hysterectomy. She presented 20 years later with a persistent right-sided pleural effusion. She underwent VATS cytoreductive pleurectomy and was found to have extensive infiltration of the pleura, the diaphragm and the pericardium with tumour. Histological examination of the tumour confirmed MPM. There was no history of significant exposure to asbestos.

The final case was a 39-year-old woman referred for the surgical treatment of a persistent right-sided pneumothorax and a right sided-pleural effusion. She had a history of nodular sclerosing Hodgkin's lymphoma involving the right lung, treated with mantle radiotherapy 14 years earlier. At operation a bulla was noted in the right lung and the right pleura was found to have a thickened and fibrous appearance, possibly attributable to the previous radio- therapy. The patient underwent VATS bullectomy and cytoreductive pleurectomy. Histological and immunohistochemical examination confirmed the diagnosis of epithelioid MPM. There was no evidence of lymphoma in the lung. A previous history of asbestos exposure was not confirmed.

\section{Discussion}

Malignant pleural mesothelioma (MPM) is an aggressive tumour derived from the lining of the pleural cavity. It frequently presents with dyspnoea and chest pain, and uncommonly with cough, fatigue and weight loss. Occasionally the diagnosis is suspected following a routine chest radiograph, with pleural thickening or a pleural effusion $[1,2]$.

The incidence of MPM is $10-30$ per million per year in unselected male populations, and approximately 2 per 


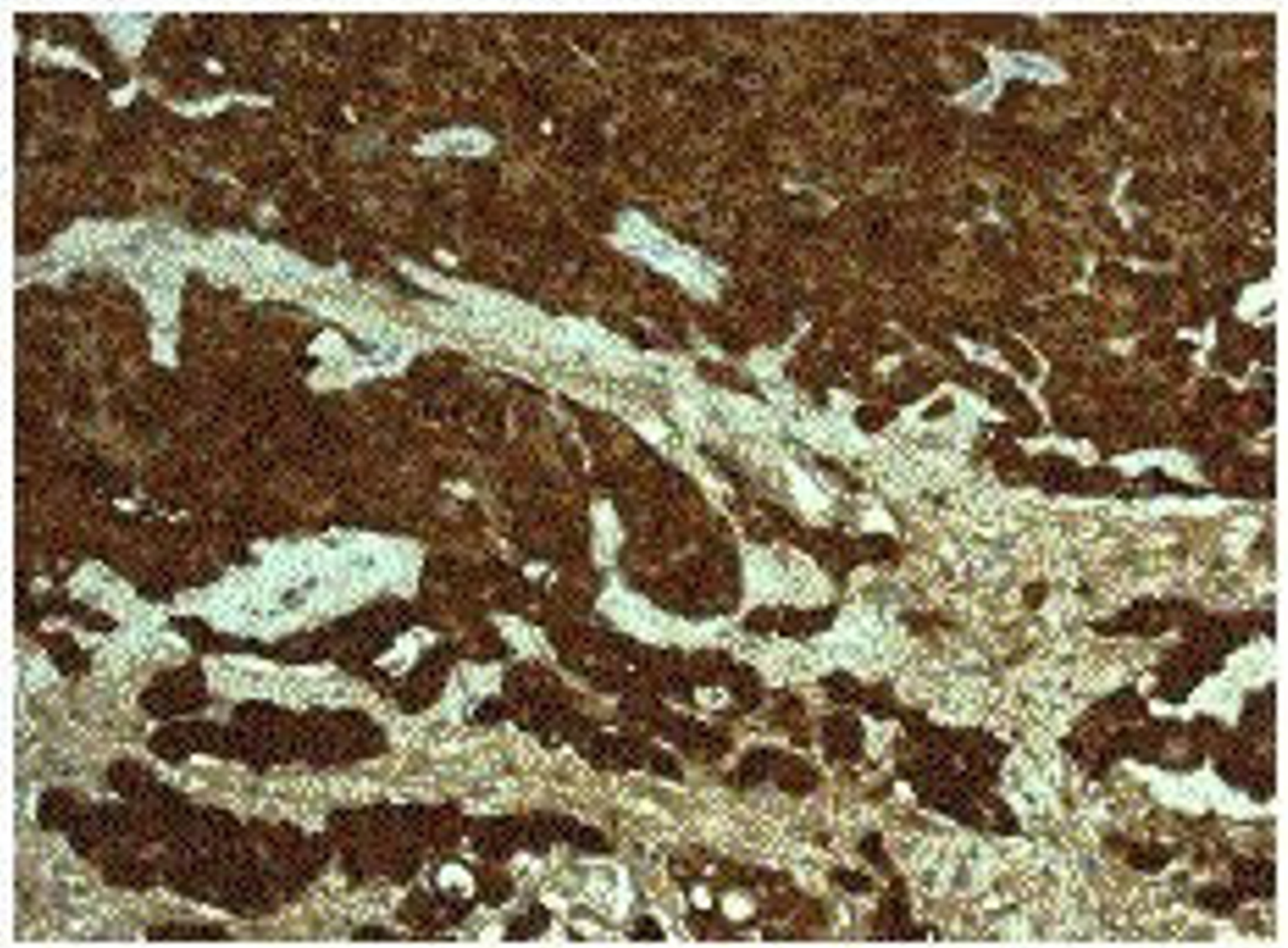

\section{Figure 2}

Histology demonstrating epithelioid mesothelioma showing positivity for the immunohistochemical marker, calretinin $\{x 200\}$.

million per year in female subjects [3]. More than 80 per cent of MPMs develop in individuals with higher than background exposure to asbestos, with an incidence as high as 366/100,000 person-years in heavily exposed workers [4]. The latent interval between first exposure to asbestos and death is very long, with a mean of 41 years and a range of 15-67 years in one series [5]. The use of 'asbestos exposure' as predictor of mesothelioma is however unreliable as many patients are unaware of such exposure or when it occurred. Other potential causative factors of MPMs include the simian virus 40 (SV40), other environmental carcinogens such as erionite, ionising radiation and genetic factors [6]. The role of radiotherapy in inducing malignancy is well described but as yet the link with mesothelioma is unclear.

MPMs have infrequently been reported in patients who had received radiotherapy (with or without chemother- apy) for previous non-pleural malignancy. Examples include the development of MPMs after radiation therapy for breast cancer [7-9], Hodgkin's lymphoma involving the lung [10-14] and Wilm's tumour with pulmonary metastasis [15]. MPM following chemotherapy alone for breast cancer has also been reported [16]. Isolated cases of concurrence of MPM with breast cancer [7-9] and Hodgkin's lymphoma [10-14] are described.

These cases highlight the importance of the systematic consideration of a diagnosis of MPM in all patients with the typical presentation of a pleural effusion, irrespective of any history of a previous malignancy (patients 1-3) and regardless of previous asbestos exposure. The incorrect assumption that a pleural effusion is caused by the known non-pleural malignancy can be a source of significant delay between presentation and referral. This delay (between 2 and 8 months in the present series) is impor- 
tant in view of the fact that survival after diagnosis of MPMs may be significantly improved as treatment strategies are developed $(17,18,19)$.

Cytological examination of the pleural aspirate in the present series was non-diagnostic. This finding is consistent with the previous reports that routine cytological examination of pleural fluid is generally unreliable for the diagnosis of MPMs, with a sensitivity of only 32\% [20]. Similarly, 'blind' percutaneous needle biopsy specimens give a diagnosis in less than $50 \%$ of cases [21]. The British Thoracic Society correspondingly recommend that a negative pleural cytology or percutaneous pleural biopsy does not exclude the diagnosis of MPM, and that ultrasound and CT-guided biopsy, and thoracoscopic and surgical biopsy techniques should be used to increase the likelihood of accurate diagnosis [17].

The use of VATS techniques in the management of malignant pleural effusions including MPM is well established [19]. It now has few complications and allows both diagnosis and therapeutic intervention to be achieved at one operative episode.

Three out of four cases in this series received significant doses of radiotherapy as part of the original treatment of their tumours. Previous cases have demonstrated the link between radiotherapy and the development of malignancy with a time frame not dissimilar to that for mesothelioma after asbestos exposure. This and other reports now suggest that the combined exposure to both asbestos and radiotherapy may be synergistic.

\section{Conclusion}

The diagnosis of malignant pleural mesotheliomas should be actively considered in all patients presenting with effusion relating to previous malignancies regardless of asbestos history. As treatment options develop for mesothelioma early and accurate diagnosis is increasingly important and best achieved by guided CT or VATS biopsy since cytology and blind needle aspiration are of low yield and may be misleading in this context. The exposure of asbestos particles to a radiotherapy field carries a theoretical risk of synergy, which requires further study [6].

\section{References}

I. Hillerdahl G: Malignant mesothelioma: a review of 4710 published cases. $\mathrm{Br} J$ Dis Chest 1983, 77:321-43.

2. Moskal TL, Urschel JD, Anderson TM, Antkowiak JG, Takita H: Malignant pleural mesothelioma: a problematic review. Surg Oncol 1998, 7:5-12.

3. McDonald JC, Sebastien P, McDonald AD: Case B: Epidemiological observations on mesothelioma and their implications for non-occupational exposure. IARC Sci Publ I 989, 90:420-7.

4. Kielkowski D, Nelson G, Rees D: Risk of mesothelioma from exposure to crocidolite asbestos: a 1995 update of a South African mortality study. Occup Environ Med 2000, 57:563-7.
5. Yates DH, Corrin B, Stidolph PN, Browne K: Malignant mesothelioma in south east England: clinicopathological experience of 272 cases. Thorax 1997, 52:507-12.

6. Carbone M, Kratzke RA, Testa JR: The pathogenesis of mesothelioma. Semin Oncol 2002, 29:2-I7.

7. Shannon VR, Nesbitt JC, Libshitz I: Malignant pleural mesothelioma after radiation therapy for breast cancer. Cancer 1995, 76:437-4I.

8. Kawashima A, Libshitz HI, Lukeman JM: Radiation-induced malignant pleural mesothelioma. Can Assoc Radiol J 1990, 4 I:384-6.

9. Antman KH, Corson JM, Li FP, Greenberger J, Sytkowski A, Henson $\mathrm{DE}$, Weinstein L: Malignant mesothelioma following radiation exposure. J Clin Oncol 1983, I:695-700.

10. Brenner J, Sordillo PP, Magill GB, Golbey RB: Malignant mesothelioma of the pleura: review of 123 patients. Cancer 1982 , 49:243I-5.

II. Lerman Y, Learman Y, Schachter P, Herceg E, Lieberman Y, Yellin A: Radiation associated malignant pleural mesothelioma. Tho$\operatorname{rax}$ 1991, 46:463-4.

12. Falchero L, Coiffier B, Gulbert B, Souquet PJ, Isaac-Pinet S, TrilletLenoir $\mathrm{V}$ : Malignant mesothelioma of the pleura following radiotherapy of Hodgkin disease. Bull Cancer 1996, 83:964-8.

13. Weissmann LB, Corson JM, Neugut Al, Antman KH: Malignant mesothelioma following treatment for Hodgkin's disease. J Clin Oncol 1996, I 4:2098-100.

14. Pappo AS, Santana VM, Furman WL, Kun LE, Walter AW, Jenkins JJ, Rao BN, Pratt CB: Post-irradiation malignant mesothelioma. Cancer 1997, 79:192-3.

15. Anderson KA, Hurley WC, Hurley BT, Ohrt DW: Malignant pleural mesothelioma following radiotherapy in a 16-year old boy. Cancer 1985, 56:273-6.

16. Melato M, Rizzardi C: Malignant pleural mesothelioma following chemotherapy for breast cancer. Anticancer Res 200I, 21:3093-6.

17. British Thoracic Society Standards of Care Committee: Statement on malignant mesothelioma in the United Kingdom. Thorax 200I, 56:250-65.

18. Treasure T, Swift S, Waller D: Radical Surgery for Mesothelioma. BMJ 2004, 328:237-238.

19. Halstead JC, Lim E, Venkateswaran RM, Charman SC, Goddard M, Ritchie AJ: Improved survival with VATS pleurectomy-decortication in advanced malignant mesothelioma. EJSO in press.

20. Renshaw AA, Dean BR, Antman KH, Sugarbaker DJ, Cibas ES: The role of cytological evaluation of pleural fluid in the diagnosis of malignant mesothelioma. Chest 1997, I I I: 106-9.

21 . Whitaker D, Shiklin KB: Diagnosis of malignant pleural mesothelioma in life: a practical approach. J Pathol 1984, |43: |47-75.

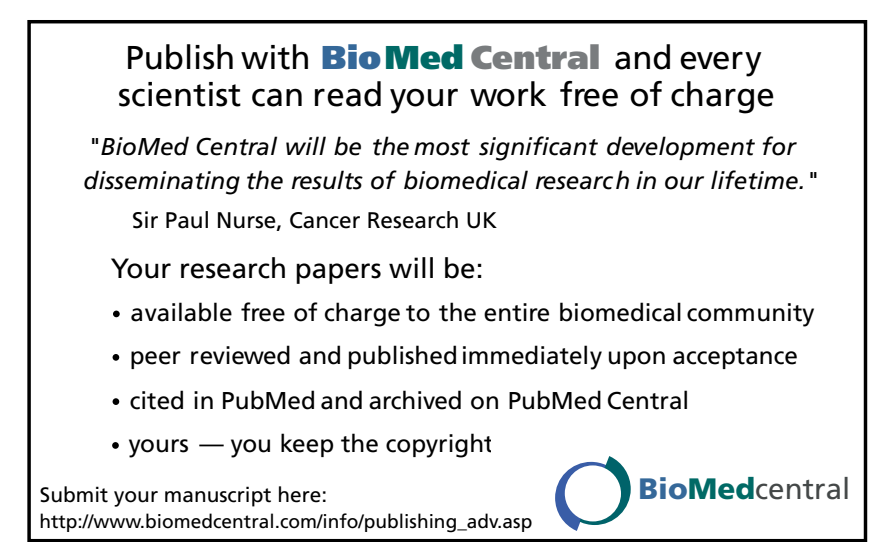

